\title{
Local knowledge and practices about fire use in wetlands management Argentina. A comparative study of fire regimes in two wetlands in Santa Fe province
}

\author{
Millán, Adriana ${ }^{l}$; Ferrero, Brián German ${ }^{l}$, Vicentini, Antonella ${ }^{l}$;ommasi, Casimiro ${ }^{l}$ e Bilbao, \\ Bibiana $^{2}$
}

\begin{abstract}
${ }^{1}$ Centro de Investigación y Transferencia (UNRaf-CONICET), Rafaela, Argentina.
2 Departamento de estudios Ambientales, Universidad Simón Bolívar, Caracas, Venezuela, bbilbao@usb.ve.

Correos electrónicos: Millán Adriana: adrianamillan@gmail.com, Ferrero Brián German: brianferrero@conicet.gov.ar, Vicentini Antonela: avsociogia@gmail.com, Tommasi Casimiro: casi.tommasi@gmail.com.
\end{abstract}

\begin{abstract}
Wetlands are one of the most vulnerable ecosystems under current and future scenarios of climate change. Variation of rain distribution patterns, increase of extreme weather events (ENSO events, intense dry and rainy periods, heat waves), and changes in fire regimes (an increase of wildfire frequency and severity) are significant challenges for the design of wetlands management and conservation strategies. Moreover, this situation threatens rural wetlands communities' sustainability, along with their local knowledge and production systems. The wetlands of Paraná River delta and those of the Submeridionals Lowlands (Santa Fe province), are located in the central Argentinian region; here, the use of burnings is a common practice to manage grasslands to feed livestock. This traditional practice is deeply rooted among local rural communities, in spite of the legal prohibition enforced by authorities. This study focuses on analyzing fire practices and knowledge applied by local rural inhabitants. Which are the underlying rationales of burning? How do they choose the areas and time of the year to burn? How do they classify the grasslands? Which are the management and cattle range load applied in burning areas? We suggest that local knowledge and practices about fire management keep the relation to new processes of land transformation, such as cattle raising expansion, infrastructure development, conservation policies, and tourist valuation of local areas. In this way, we understand that local knowledge and practices originate through long regional historical processes, tightly related to land transformation and recent cattle development activities. Discussions about local knowledge historical perspectives concerning ecological aspects may allow finding alternative and sustainable ways of conservation. This new strategy will focus on enhancing transformative processes from previous fire suppression policies towards participative schemes that integrate rural communities, their living purposes and their production activities.
\end{abstract}

Keywords: fire, local knowledge, rural communities, wetlands conservation and management, grasslands, cattle raising, Argentina 